\title{
Flu-virus prevalence comes under scrutiny
}

\section{Projects to monitor antibodies seek true extent of H1N1 infection.}

Researchers are turning their attention to one of the great unknowns about the ongoing H1N1 influenza pandemic: how many people have been, and are being, infected. The first surveys to monitor for antibodies to the virus are now getting under way, belatedly in some countries such as the United States. The findings could substantially change much of what epidemiologists know about the current pandemic.

"I'm very struck that we don't have even an idea of the magnitude of infection," says Xavier de Lamballerie, a virologist at the University of the Mediterranean Aix-Marseille II in Marseilles, France. "Epidemiologists haven't a clue if it is $5 \%, 10 \%$ or $20 \%$ of the population."

Gathering that information is crucial for improving estimates of pandemic spread, severity and mortality, and informing policies such as how to distribute vaccines and antiviral drugs.

Laboratory-confirmed cases of pandemic $\mathrm{H} 1 \mathrm{~N} 1$ underestimate the true prevalence by several orders of magnitude, as only a tiny fraction of cases can be tested. Instead, publichealth agencies such as the US Centers for Disease Control and Prevention (CDC) in Atlanta, Georgia, use proxy measures, including data on the frequency of people reporting influenzalike symptoms to their doctors.

But testing blood samples for antibodies to pandemic $\mathrm{H} 1 \mathrm{~N} 1$ is the only definitive way to establish how many people have been exposed to the virus and to begin to estimate how this is changing over time. "Arguably, these data are one of the most important quantities," says Marc Lipsitch, an epidemiologist at the Harvard School of Public Health in Boston, Massachusetts, who is working with the CDC on pandemic flu.

Britain, France and Vietnam are among those farthest ahead with such studies for H1N1. In Britain, Andrew Hayward heads FluWatch, which for the pandemic has scaled up its seasonal-flu work to a $£ 2.1$-million (US\$3.5million) study co-funded by the Medical

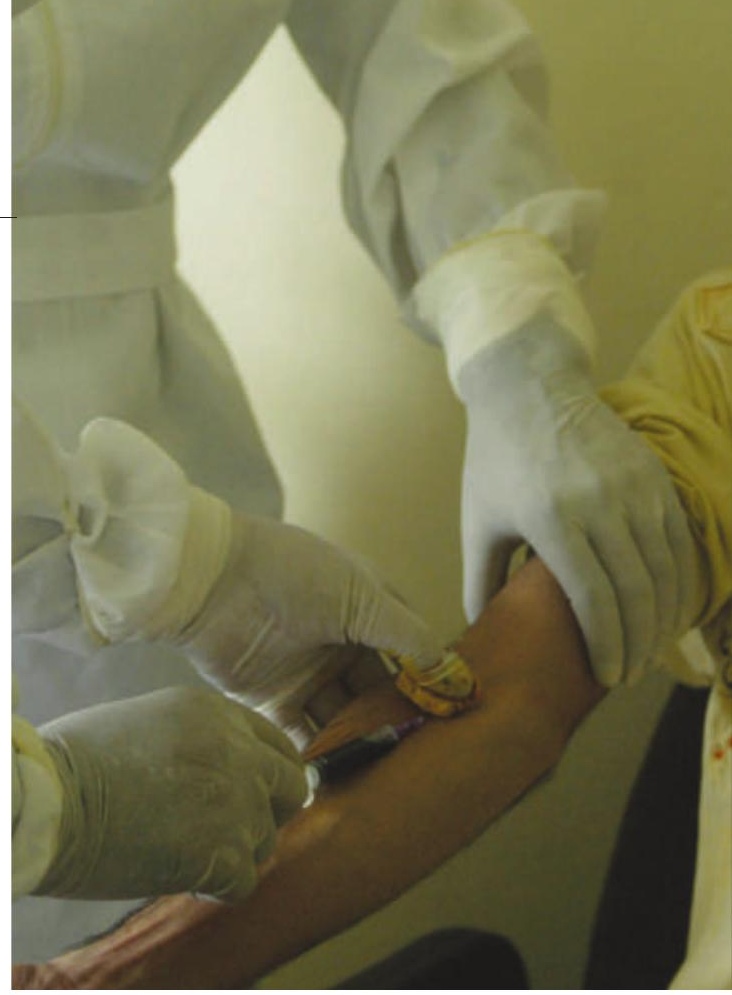

Research Council and the Wellcome Trust. Instead of its usual 650-850 subjects, the group will investigate 10,000 subjects, including 2,500 in a serology study to look for antibodies against $\mathrm{H} 1 \mathrm{~N} 1$ in their blood serum.

The UK Health Protection Agency has also launched a $£ 180,000$ study. This draws on blood samples collected from hospital patients for other purposes - so what it lacks in terms of targeting well-characterized groups of individuals, it makes up for in speed by using

\section{Japan sets sights on solar power from space}

Japanese scientists are once again eyeing an off-world approach to alternative energy - collecting solar energy from satellites in orbit and beaming it down to Earth.

A space-based solar-power satellite - which could gather energy without having to worry about clouds or night-time - has been a dream for decades in both the United States and Japan. But the costs of developing it has meant that support has waxed and waned over the years. Now, however, Japan has a new sense of mission. In June, it released a national space plan calling for a programme to "lead the world in space-based solar power". And earlier this month, scientists, engineers and policy-makers met at Kyoto University to lay out development plans.

The government's commitment "is definitely a milestone and has given tremendous excitement to solar-power satellite researchers", says Hiroshi Matsumoto, a radio scientist and president of Kyoto University.

Researchers are hoping to launch a full-scale system by 2030 , but costs need to come down dramatically for it to be economically viable.

\section{Few doubt} that the project is technically possible. The wellunderstood process starts with collecting solar energy with photovoltaic cells, transferring that energy to antennas that transmit microwaves, then receiving those microwaves with a 'rectifying antenna' that converts them to electricity. As early as 1975, scientists at the Jet Propulsion Laboratory in Pasadena, California, transferred energy by means of microwaves over a distance of 1.54 kilometres. And in May last year, scientists beamed power over a distance of 148 kilometres, between two Hawaiian islands. Japan has been investigating solarpower satellites since the 1980s. In 1983 and again in 1993, Matsumoto, working with Kobe University's Nobuyuki Kaya, launched rockets into the ionosphere to investigate what happens to microwaves as they travel through space (H. Matsumoto Radio Sci. Bull. 273, 11-35; 1995). In March this year, a group from Kyoto University became the first to use microwaves to send power from the air to the ground when they charged a mobile phone with microwaves transmitted from a blimp-like airship hovering some 30 metres above the ground.

Current scale-up plans call for a series of tests, each with an increasingly larger capacity for power transmission. First, Japan aims to demonstrate groundbased transmission in the kilowatt range, then space-based kilowatt transmission using Japan's Kibo module on the International Space Station or small satellites. By 2020, researchers hope to have a prototype satellite that can transmit in the range of hundreds of kilowatts, and by 2030 a satellite that can transmit a gigawatt. As currently envisioned, the system to launch in 2030 would be a 2-kilometre-wide array of 


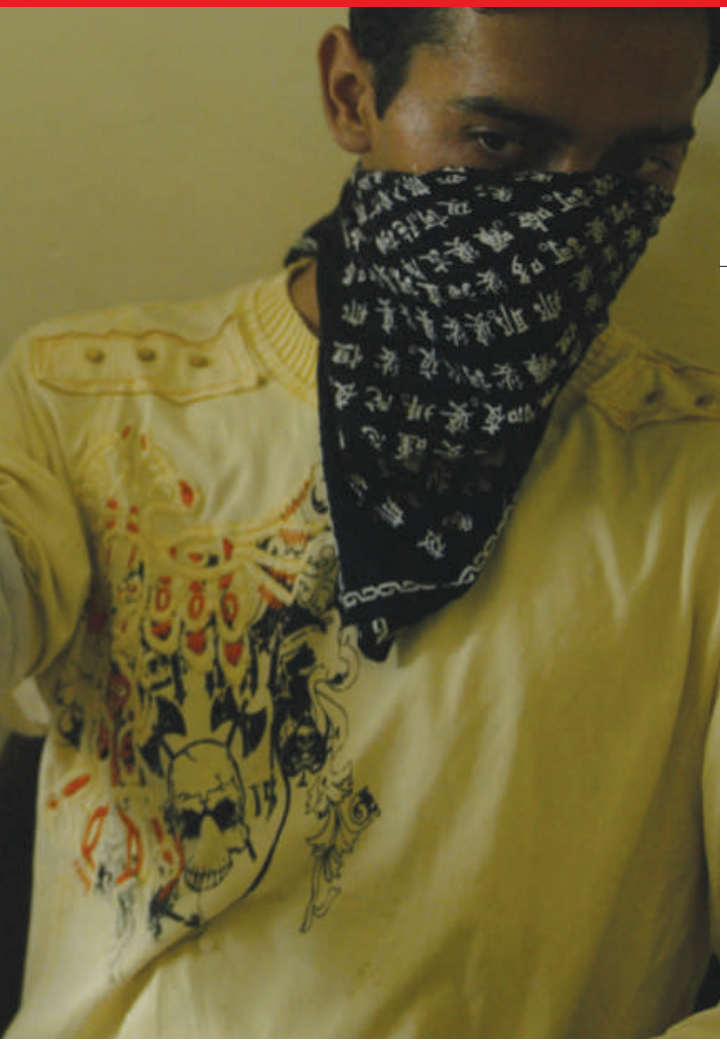

Antibody analysis of blood samples is the only way to accurately track the evolving flu pandemic.

existing samples. Survey leaders have collected 1,403 blood samples from before the first pandemic wave, and 1,954 taken in August and September, across all age groups from eight regions in England. "I believe England is the first to obtain such seroincidence data," says Elizabeth Miller, the study's lead researcher.

She declined to comment on the results because they are under review at a journal, but says the data will provide "insight into the extent to which surveillance has underestimated the true burden of infection due to the occurrence of mild or asymptomatic infections". Hayward is also writing up preliminary FluWatch results gathered during Britain's first pandemic wave, and these too are likely to show a very different picture from that provided by surveillance data alone.

In France, the second wave of the pandemic has only just begun, buying precious time for the $€ 300,000$ (US\$450,000) SéroGrippeHebdo ('Sero Flu
"Arguably, these data are one of the most important quantities." in 269 households in the northern Ha Nam province to study the serology of pandemic flu. Horby says it should yield good data on the true epidemiology of H1N1 in Vietnam.

Other projects are also just getting started. On top of the survey of pregnant women, Antoine Flahault, dean of the French School of Public Health, is seeking support for a French-led international study called CoPanFlu. This would see each partner fully profile 1,000 households during the pandemic, including serology testing at sixmonthly intervals over two years.

"One shouldn't underestimate Weekly') study, led by the French School of Public Health in Rennes and Paris. This project is recruiting 30,000 pregnant women, and gains speed by piggybacking on existing infrastructure for routine blood sampling of this group. It will publish serology data from 800 of the women weekly in real time, beginning this week. Already, says de Lamballerie, whose lab is doing the testing, "we've got a great baseline - no higher than $5 \%$ or so of the study population has already been infected".

In Vietnam, Peter Horby, a researcher at the National Institute for Infectious and Tropical Diseases in Hanoi, is part of a project testing leftover serum from haematology and biochemistry labs in nine provincial hospitals. He is also switching a seasonal-flu study of 908 people the difficulty in getting these sorts of studies off the ground," says Hayward.

The United States was less prescient, it seems. Academic groups there are still in the process of applying for funds for such surveys, and Nature has also learned that the CDC is about to announce a serology study across ten states. During pandemic planning before the current virus arose, the United States extensively discussed the need for such studies but decisions weren't taken, says Donald Burke, dean of the Graduate School of Public Health at the University of Pittsburgh in Pennsylvania: "None of these very important studies were in place when we knew there was going to be a pandemic. It's unfortunate."

Declan Butler solar cells with an array of 1 billion transmitting antennas - each measuring $5-10$ centimetres across — on the side facing Earth.

The goal is to make satellites for under $¥ 1$ trillion (US $\$ 11$ billion) each; it currently costs 100 times that. "It's exciting, but there are many problems to overcome," says Naoki Shinohara of Kyoto University. For one thing, transmission efficiency must rise to $75 \%$, he says; the airship experiment achieved just $40 \%$ efficiency, although the technology it uses differs from what a satellite would use.

Rocket launches will also need to be cut to a hundredth of their current cost; options such as reusable rockets are being considered, according to Susumu Sasaki of the Japan Aerospace Exploration Agency (JAXA). At this month's meeting, Tokyo University's Kimiya Komurasaki discussed how

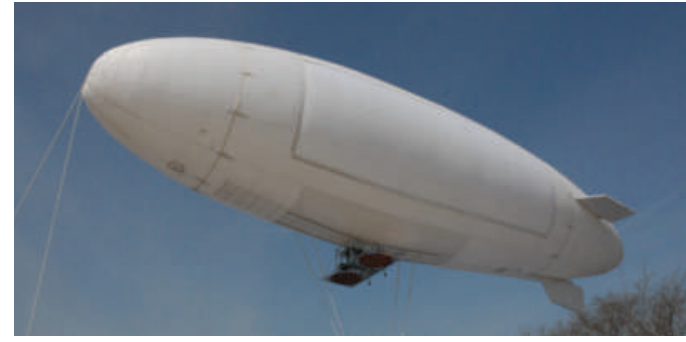

Experiments this year with an airship transmitted enough power to charge a mobile phone on the ground.

a remote microwave source could power rockets. That would reduce the amount of propellant they need to carry and, in theory, mean that rockets used to build a solar-power satellite could carry more antennas and solar cells.

Matsumoto estimates that it will take $¥ 2$ billion to $¥ 3$ billion to demonstrate solar-power satellite technology on the ground, and $¥ 10$ billion to $¥ 50$ billion to demonstrate it in orbit.

The nation's space plan calls for an "all-Japan" effort to prepare for space-based demonstrations within three years. And as research budgets have been tight in many areas (see Nature 462, 258-259; 2009), the industry and science ministries have more than doubled their budget requests for solarpower satellite-related programmes, to nearly $¥ 1.4$ billion. JAXA has pressed for a doubling of its budget for space-based solar power, from $¥ \mathbf{2 5 0}$ million to $¥ 500$ million.

"I'm $100 \%$ confident this [technology] will happen," says Shinohara. Unlike wind or Earthbased solar, solar-power satellites in space can gather energy 24 hours a day to provide a reliable source of alternative energy. "We need another stable power source," he says.

Japan looks likely to lead the way, as interest in the United States has waned, says John Mankins, who led the space solar-power programme at NASA. Most efforts in the United States are now in private companies or non-profit organizations. In April, Solaren, a company based in Manhattan Beach, California, signed a contract with San Franciscobased Pacific Gas and Electric to produce $\mathbf{2 0 0}$ megawatts of energy from a solar-power satellite starting in 2016. But Mankins, who co-founded and works at Managed Energy Technologies in Ashburn, Virginia, calls that goal "extremely challenging".

Japan's effort, he says, may lead the way: "The Japanese plan is quite well formulated."

David Cyranoski 